\title{
Wpływ gęstości medium na ciśnienie wyjściowe reduktora średniego ciśnienia
}

\begin{abstract}
W artykule przedstawiono sposób przeliczania strumienia objętości gazów oraz korelację między gęstością medium a charakterystykami przepływu reduktora średniego ciśnienia.

Słowa kluczowe: reduktor, gęstość, strumień objętości.

\section{Influence of gas density on the output pressure of a medium pressure reducing regulator}

The article demonstrates how to convert a stream of gas volume and the correlation between gas density and the characteristics of the flow of a medium pressure reducing regulator.
\end{abstract}

Key words: regulator, density, volume flow.

\section{Wprowadzenie}

Reduktor średniego ciśnienia jest jednym z głównych elementów punktu gazowego usytuowanego pomiędzy siecią średniego ciśnienia a instalacją gazową [2].

Punkt gazowy znajduje się na przyłączu i służy do redukcji ciśnienia i do pomiaru ilości gazu ziemnego o strumieniu objętości do $60 \mathrm{~m}^{3} / \mathrm{h}$ włącznie i o maksymalnym ciśnieniu roboczym na wejściu do 0,5 MPa włącznie [5].

Zadaniem reduktora jest regulacja ciśnienia wyjściowego na stałym poziomie oraz uzyskanie zadeklarowanego przez producenta znamionowego strumienia objętości w zakresie ciśnień wejściowych od $10 \mathrm{kPa}$ do 0,5 MPa. Obecnie ciśnienie wyjściowe według wymagań powinno wynosić: $1,3^{ \pm 0,15} \mathrm{kPa}$ lub $2,0^{ \pm 0,2} \mathrm{kPa}$, zależnie od wykonania fabrycznego reduktora.

Regulacja ciśnienia w zależności od budowy reduktora może być jedno- lub dwustopniowa:

- Regulacja jednostopniowa działa tak, że przez przejście gazu z komory średniego ciśnienia do komory niskiego ciśnienia redukuje bezpośrednio ciśnienie z sieci na ciśnienie wyjściowe.

- Regulacja dwustopniowa posiada dwa stopnie rozprężania gazu: pierwszy stopień rozprężania następuje w komorze średniego ciśnienia przez przejście gazu z komory wyższego ciśnienia. Zachodzi to samoczynnie dzięki odpowiedniemu ustawieniu śruby nastawnej. Drugi stopień rozprężania gazu odbywa się w komorze niskiego ciśnienia.

Reduktory dwustopniowe są częściej stosowane, ponieważ stabilniej niż reduktory jednostopniowe utrzymują ciśnienie wyjściowe przy zmiennym poborze gazu.

Reduktory średniego ciśnienia posiadają we wspólnym korpusie wbudowane, oprócz właściwych regulatorów ciśnienia, także urządzenia zabezpieczające, chroniące gazową instalację domową przed przekroczeniem granicznych ciśnień roboczych [4]. Dla zapewnienia bezpieczeństwa każdy reduktor powinien być wyposażony w:

- zabezpieczenia przed wzrostem ciśnienia wylotowego,

- zabezpieczenia przed spadkiem ciśnienia wylotowego,

- wydmuchowy zawór upustowy,

- filtr przeciwpyłowy.

Zabezpieczenie przed wzrostem oraz spadkiem ciśnienia wylotowego jest realizowane poprzez zawór szybkozamykający. Wzrost ciśnienia gazu w instalacji może powstać wskutek awarii reduktora. Zawór ten pracuje w pozycji otwartej na zasadzie mechanizmu zapadkowego i ma na celu natychmiastowe zamknięcie przepływu gazu w przypadku nadmiernego wzrostu lub spadku ciśnienia gazu za reduktorem. 
Ciśnienie zamknięcia zaworu szybkozamykającego przy wzroście ciśnienia wyjściowego powinno być wyższe od ciśnienia zadziałania wydmuchowego zaworu upustowego.

Powtórne uruchomienie może nastąpić tylko przy ingerencji człowieka.

Zabezpieczenie przed spadkiem ciśnienia wyjściowego/ wejściowego może być również realizowane poprzez zawór odcinający. Spadek ciśnienia wyjściowego może nastąpić na skutek nieszczelności instalacji, awarii reduktora, ale także po uruchomieniu odbiorników o dużym poborze gazu. Jest to spowodowane dużą bezwładnością reduktora - odbiornik zaczyna pobierać gaz z instalacji, a reduktor nie zdążył się otworzyć. Zawór działa również przy zaniku ciśnienia wejściowego - przy spadku ciśnienia w sieci następuje spadek ciśnienia w instalacji, co powoduje zadziałanie zaworu odcinającego.

Otwieranie zaworu powinno być manualne, zabezpieczone przed przypadkowym zadziałaniem, przy czym dopuszcza się automatyczne otwieranie zaworu odcinającego z zastrzeżeniem, że otwarcie to uwarunkowane jest przywróceniem wartości ciśnienia wyjściowego (w instalacji za reduktorem) strumieniem objętości gazu nie większym niż $30 \mathrm{dm}^{3} / \mathrm{h}$ [7].

Wydmuchowy zawór upustowy jest wbudowany w korpus i ma za zadanie odprowadzić nadmiar ciśnienia gazu, jeżeli w instalacji wystąpiło niewielkie zwiększenie się ciśnienia. Może ono być spowodowane wzrostem temperatury lub nagłym zanikiem poboru gazu w instalacji gazowej. W momencie wzrostu ciśnienia gazu na wylocie ponad ciśnienie nastawy sprężyna ulega ściśnięciu, a zawór upustowy otwiera się, powodując upuszczenie gazu do atmosfery w ilościach nie większych niż $2 \%$ wartości strumienia nominalnego reduktora. Po obniżeniu ciśnienia do wymaganego poziomu zawór samoczynnie się zamyka.

$\mathrm{Na}$ wlocie reduktora znajduje się filtr przeciwpyłowy, który zabezpiecza przed zanieczyszczeniami z sieci.

Dla potwierdzenia prawidłowego działania regulatora ciśnienia oraz urządzeń zapewniających bezpieczeństwo obecnych w reduktorze średniego ciśnienia producent wystawia deklarację zgodności wyrobu.

\section{Wymagania dotyczące reduktorów średniego ciśnienia - ciśnienie wyjściowe}

Zgodnie z rozporządzeniem Ministra Infrastruktury z dnia 11 sierpnia 2004 r. w sprawie sposobów deklarowania zgodności wyrobów budowlanych oraz sposobu znakowania ich znakiem budowlanym (Dz. U. z 2004 Nr 198, poz. 2041 ze zm.) [6] reduktory średniego ciśnienia podlegają ocenie zgodności w systemie 3, czyli deklarowanie zgodności wyrobu przez producenta dokonuje się poprzez:

- wstępne badania typu prowadzone przez akredytowane laboratorium,

- zakładową kontrolę produkcji (ZKP) [3].

Badanie typu jest wykonywane na podstawie zaleceń aprobacyjnych [7], które należy wykonać w następujących przypadkach:

- przy pierwszym zastosowaniu zaleceń aprobacyjnych [7] przed wprowadzeniem wyrobu na rynek,

- przy rozpoczynaniu produkcji nowych lub projektowo zmodyfikowanych wyrobów,
- przy wdrażaniu nowej produkcji, jeśli może ona wpłynąć na określone właściwości wyrobu.

Aby reduktor mógł przejść pozytywnie badania typu, musi spełnić wymagania konstrukcyjne i funkcjonalne. Jednym z badań funkcjonalnych jest sprawdzenie ciśnienia wyjściowego. Polega ono na wyznaczeniu charakterystyki przepływowej. Charakterystyka pokazuje zależność ciśnienia wyjściowego od strumienia objętości powietrza przy stałej wartości ciśnienia wejściowego. Wyznacza się ją przy co najmniej trzech wartościach ciśnienia wejściowego. Wartość ciśnienia wyjściowego powinna się mieścić w granicach:

- $1,3^{ \pm 0,15} \mathrm{kPa}$ dla wykonania $1,3 \mathrm{kPa}$,

- $2,0^{ \pm 0,2} \mathrm{kPa}$ dla wykonania $2 \mathrm{kPa}$.

Badania te ze względu na bezpieczeństwo przeprowadza się, stosując jako medium powietrze. Po badaniu należy przeliczyć strumień objętości gazu ziemnego ze strumienia objętości powietrza, uwzględniając różnicę gęstości tych gazów.

\section{Sposób przeliczania objętości gazów}

Do przeliczania strumienia objętości wykorzystano wzór [1]

$$
Q_{x}=Q_{v} \sqrt{\frac{\rho_{v}}{\rho_{x}}}
$$

gdzie:

$Q_{x}$ - strumień objętości gazu przeliczanego,

$Q_{v}$ - strumień objętości gazu mierzonego, $\rho_{v}$ - gęstość gazu mierzonego,

$\rho_{x}-$ gęstość gazu przeliczanego.

W pracy statutowej [1] przedstawiono sposób wyprowadzenia wzoru (1) dla gazomierzy miechowych. Przyjęto, że przepływ medium innego niż powietrze powinien powodować spadek ciśnienia $\mathrm{w}$ gazomierzu na takim samym poziomie. Spadek ciśnienia (opór) w gazomierzach miechowych 
jest powodowany przez opory hydrauliczne i mechaniczne układu kinetycznego gazomierza. Opór $(P)$ gazomierza został przedstawiony w ogólnej postaci:

$$
P=\rho \cdot V^{2} \cdot F
$$

gdzie:

$\rho$ - gęstość płynu,

$V$ - prędkość płynu,

$F$ - pole powierzchni czołowej ciała stawiającego opór.

Z równania (2) wynika, że w przypadku wzrostu gęstości płynu, przy stałej prędkości płynu i powierzchni oporu, następuje zwiększenie się spadku ciśnienia (oporu) w gazomierzu. W warunkach geometrycznego podobieństwa przepływów, na podstawie zasady zachowania pędu, zachodzi:

$$
P_{1}=P_{2}
$$

gdzie:

$$
P_{1}=\rho_{1} \cdot V_{1}^{2} \cdot F_{1} \text { oraz } P_{2}=\rho_{2} \cdot V_{2}^{2} \cdot F_{2}
$$

po podstawieniu (4) do (3) uzyskujemy:

$$
\rho_{1} \cdot V_{1}^{2} \cdot F_{1}=\rho_{2} \cdot V_{2}^{2} \cdot F_{2}
$$

przy czym:

$$
V_{1}=\frac{Q_{1}}{F_{1}} \operatorname{oraz} V_{2}=\frac{Q_{2}}{F_{2}}
$$

Przyjmując, że $F_{1}=F_{2}$, oraz podstawiając (6) do (5), otrzymamy:

$$
Q_{2}=Q_{1} \sqrt{\frac{\rho_{1}}{\rho_{2}}}
$$

Przyjmując, że $Q_{1}$ i $\rho_{1}$ sa to odpowiednio strumień objętości gazu mierzonego $Q_{v}$ oraz gęstość gazu mierzonego $\rho_{v}$, $Q_{2}$ i $\rho_{2}$ oznaczają odpowiednio strumień objętości gazu przeliczanego $Q_{x}$ oraz gęstość gazu przeliczanego $\rho_{x}$, otrzymamy wzór (1). Stosunek $\sqrt{\frac{\rho_{v}}{\rho_{x}}}$ można potraktować jako współczynnik do przeliczania strumienia objętości.

Poniżej podano przykład przeliczenia strumienia objętości powietrza ze strumienia objętości:

- azotu:

$$
Q_{x}=1,8 \sqrt{\frac{1,25}{1,29}}=1,77 \mathrm{~m}^{3} / \mathrm{h}
$$

- $\operatorname{argonu}$

$$
Q_{x}=1,3 \sqrt{\frac{1,78}{1,29}}=1,53 \mathrm{~m}^{3} / \mathrm{h}
$$

- dwutlenku węgla:

$$
Q_{x}=1,3 \sqrt{\frac{1,96}{1,29}}=1,60 \mathrm{~m}^{3} / \mathrm{h}
$$

\begin{tabular}{|c|c|c|c|c|c|}
\hline \multirow{2}{*}{$\begin{array}{c}\text { Ciśnienie } \\
\text { wlotowe } \\
{[\mathrm{MPa}]}\end{array}$} & Dysza $4 \mathrm{~mm}$ & Dysza $6 \mathrm{~mm}$ & Dysza $8 \mathrm{~mm}$ & Dysza $9 \mathrm{~mm}$ & \multirow[b]{2}{*}{ Reduktor } \\
\hline & $\begin{array}{c}\text { przepływ } \\
{\left[\mathrm{m}^{3} / \mathrm{h}\right]}\end{array}$ & $\begin{array}{c}\text { przepływ } \\
{\left[\mathrm{m}^{3} / \mathrm{h}\right]}\end{array}$ & $\begin{array}{c}\text { przepływ } \\
{\left[\mathrm{m}^{3} / \mathrm{h}\right]}\end{array}$ & $\begin{array}{c}\text { przepływ } \\
{\left[\mathrm{m}^{3} / \mathrm{h}\right]}\end{array}$ & \\
\hline 0,1 & 1,6 & 4,6 & 7,4 & 10,7 & A \\
\hline 0,1 & 1,6 & 4,6 & 7,4 & 10,5 & B \\
\hline 0,1 & 1,6 & 4,6 & 7,4 & reduktor wyłączył się & $\mathrm{C}$ \\
\hline
\end{tabular}

\section{Wyniki badań}

\begin{tabular}{|c|c|c|c|c|c|c|c|c|c|}
\hline \multirow{3}{*}{$\begin{array}{c}\text { Ciśnienie } \\
\text { wlotowe } \\
{[\mathrm{MPa}]}\end{array}$} & \multirow{2}{*}{\multicolumn{2}{|c|}{$\begin{array}{c}\text { Dysza } 4 \mathrm{~mm} \\
\text { przepływ } \\
{\left[\mathrm{m}^{3} / \mathrm{h}\right]}\end{array}$}} & \multirow{2}{*}{\multicolumn{2}{|c|}{$\begin{array}{c}\text { Dysza } 6 \mathrm{~mm} \\
\text { przepływ } \\
{\left[\mathrm{m}^{3} / \mathrm{h}\right]}\end{array}$}} & \multirow{2}{*}{\multicolumn{2}{|c|}{$\begin{array}{c}\text { Dysza } 8 \mathrm{~mm} \\
\text { przepływ } \\
{\left[\mathrm{m}^{3} / \mathrm{h}\right]}\end{array}$}} & \multirow{2}{*}{\multicolumn{2}{|c|}{$\begin{array}{c}\text { Dysza } 9 \mathrm{~mm} \\
\text { przepływ } \\
{\left[\mathrm{m}^{3} / \mathrm{h}\right]}\end{array}$}} & \multirow{3}{*}{ Reduktor } \\
\hline & & & & & & & & & \\
\hline & zmierzony & przeliczony & zmierzony & przeliczony & zmierzony & przeliczony & zmierzony & przeliczony & \\
\hline 0,1 & 1,3 & 1,53 & 3,9 & 4,58 & 6,5 & 7,64 & 9,2 & 10,81 & A \\
\hline 0,1 & 1,3 & 1,53 & 3,8 & 4,46 & 6,2 & 7,28 & 8,5 & 10,57 & B \\
\hline 0,1 & 1,3 & 1,53 & 3,8 & 4,46 & 6,2 & 7,28 & $\begin{array}{c}\text { reduktor } \\
\text { wyłączył się }\end{array}$ & $\begin{array}{c}\text { reduktor } \\
\text { wyłączył się }\end{array}$ & $\mathrm{C}$ \\
\hline
\end{tabular}

W tablicach od 1 do 4 przedstawiono wyniki badań strumienia objętości dla trzech różnych reduktorów $\mathrm{A}, \mathrm{B}, \mathrm{C}$ dla powietrza oraz innych gazów.
Tablica 1. Wyniki badań strumienia objętości dla powietrza

Tablica 2. Wyniki badań strumienia objętości dla argonu 
Tablica 3. Wyniki badań strumienia objętości dla azotu

\begin{tabular}{|c|c|c|c|c|c|c|c|c|c|}
\hline \multirow{3}{*}{$\begin{array}{c}\text { Ciśnienie } \\
\text { wlotowe } \\
{[\mathrm{MPa}]}\end{array}$} & \multirow{2}{*}{\multicolumn{2}{|c|}{$\begin{array}{c}\text { Dysza } 4 \mathrm{~mm} \\
\text { przepływ } \\
{\left[\mathrm{m}^{3} / \mathrm{h}\right]}\end{array}$}} & \multirow{2}{*}{\multicolumn{2}{|c|}{$\begin{array}{c}\text { Dysza } 6 \mathrm{~mm} \\
\text { przepływ } \\
{\left[\mathrm{m}^{3} / \mathrm{h}\right]}\end{array}$}} & \multirow{2}{*}{\multicolumn{2}{|c|}{$\begin{array}{c}\text { Dysza } 8 \mathrm{~mm} \\
\text { przepływ } \\
{\left[\mathrm{m}^{3} / \mathrm{h}\right]}\end{array}$}} & \multirow{2}{*}{\multicolumn{2}{|c|}{$\begin{array}{c}\text { Dysza } 9 \mathrm{~mm} \\
\text { przeplyw } \\
{\left[\mathrm{m}^{3} / \mathrm{h}\right]}\end{array}$}} & \multirow{3}{*}{ Reduktor } \\
\hline & & & & & & & & & \\
\hline & zmierzony & przeliczony & zmierzony & przeliczony & zmierzony & przeliczony & zmierzony & przeliczony & \\
\hline 0,1 & 2,0 & 2,0 & 4,9 & 4,9 & 7,8 & 7,8 & 10,9 & 10,9 & A \\
\hline 0,1 & 1,6 & 1,6 & 4,6 & 4,6 & 7,8 & 7,8 & 10,9 & 10,9 & B \\
\hline 0,1 & 1,8 & 1,8 & 4,6 & 4,6 & 7,4 & 7,4 & $\begin{array}{c}\text { reduktor } \\
\text { wyłączył się }\end{array}$ & $\begin{array}{c}\text { reduktor } \\
\text { wyłączył się }\end{array}$ & $\mathrm{C}$ \\
\hline
\end{tabular}

Tablica 4. Wyniki badań strumienia objętości dla dwutlenku węgla

\begin{tabular}{|c|c|c|c|c|c|c|c|c|c|}
\hline \multirow{3}{*}{$\begin{array}{c}\text { Ciśnienie } \\
\text { wlotowe } \\
{[\mathrm{MPa}]}\end{array}$} & \multicolumn{2}{|c|}{ Dysza $4 \mathrm{~mm}$} & \multicolumn{2}{|c|}{ Dysza $6 \mathrm{~mm}$} & \multicolumn{2}{|c|}{ Dysza $8 \mathrm{~mm}$} & \multicolumn{2}{|c|}{ Dysza $9 \mathrm{~mm}$} & \multirow{3}{*}{ Reduktor } \\
\hline & \multicolumn{2}{|c|}{$\begin{array}{c}\text { przepływ } \\
{\left[\mathrm{m}^{3} / \mathrm{h}\right]}\end{array}$} & \multicolumn{2}{|c|}{$\begin{array}{c}\text { przepływ } \\
{\left[\mathrm{m}^{3} / \mathrm{h}\right]}\end{array}$} & \multicolumn{2}{|c|}{$\begin{array}{c}\text { przepływ } \\
{\left[\mathrm{m}^{3} / \mathrm{h}\right]}\end{array}$} & \multicolumn{2}{|c|}{$\begin{array}{c}\text { przepływ } \\
{\left[\mathrm{m}^{3} / \mathrm{h}\right]}\end{array}$} & \\
\hline & zmierzony & przeliczony & zmierzony & przeliczony & zmierzony & przeliczony & zmierzony & przeliczony & \\
\hline 0,1 & 1,3 & 1,6 & 3,8 & 4,68 & 6,2 & 7,64 & 8,6 & 10,60 & A \\
\hline 0,1 & 1,3 & 1,6 & 3,7 & 4,56 & 6,1 & 7,52 & 8,4 & 10,35 & $\mathrm{~B}$ \\
\hline 0,1 & 1,3 & 1,6 & 3,7 & 4,56 & 5,9 & 7,27 & $\begin{array}{c}\text { reduktor } \\
\text { wyłączył się }\end{array}$ & $\begin{array}{c}\text { reduktor } \\
\text { wyłączył się }\end{array}$ & $\mathrm{C}$ \\
\hline
\end{tabular}

\section{Wyznaczenie korelacji}

Przedstawioną korelację wyznaczono między charakterystykami przepływu a gęstością medium. Pomiar strumienia objętości wykonano dla trzech różnych reduktorów przy ciśnieniu wejściowym 0,1 MPa. Do oceny korelacji przyjęto współczynnik liniowy korelacji Pearsona, który służy do badania liniowej zależności między danymi.

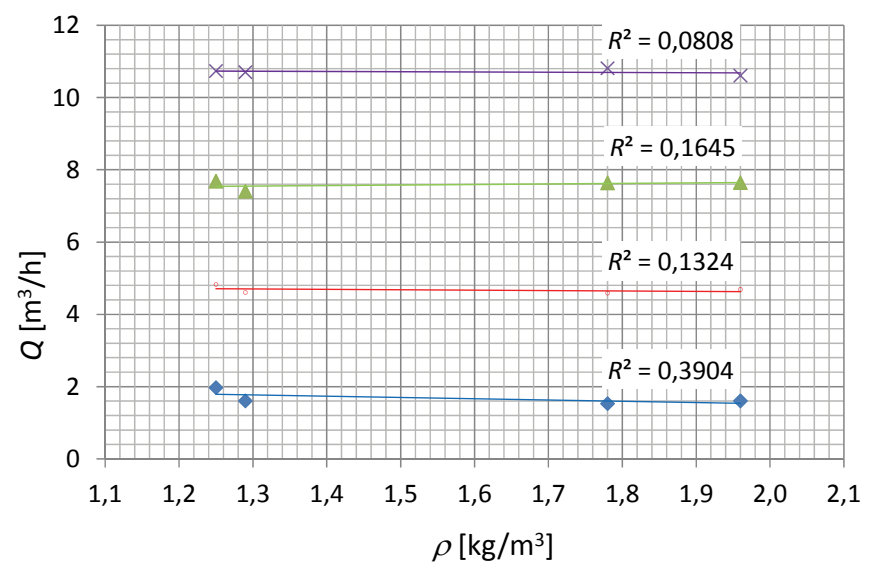

- Przepływ $\left[\mathrm{m}^{3} / \mathrm{h}\right]$ - dysza $4 \mathrm{~mm}$-Przepływ $\left[\mathrm{m}^{3} / \mathrm{h}\right]$ - dysza $6 \mathrm{~mm}$

$\triangle$ Przepływ $\left[\mathrm{m}^{3} / \mathrm{h}\right]$ - dysza $8 \mathrm{~mm} \quad \times$ Przepływ $\left[\mathrm{m}^{3} / \mathrm{h}\right]-$ dysza $9 \mathrm{~mm}$

Rys. 1. Korelacja między gęstością medium a charakterystykami przepływu reduktora $\mathrm{A}$ przy ciśnieniu wejściowym $0,1 \mathrm{MPa}$
Siła korelacji według współczynnika liniowego korelacji |r|:

1. $<0,2$ - brak korelacji,

2. $0,2 \div 0,4-$ słaba zależność,

3. $0,4 \div 0,7$ - umiarkowana zależność,

4. $0,7 \div 0,9-$ dość silna zależność,

5. >0,9-bardzo silna zależność.

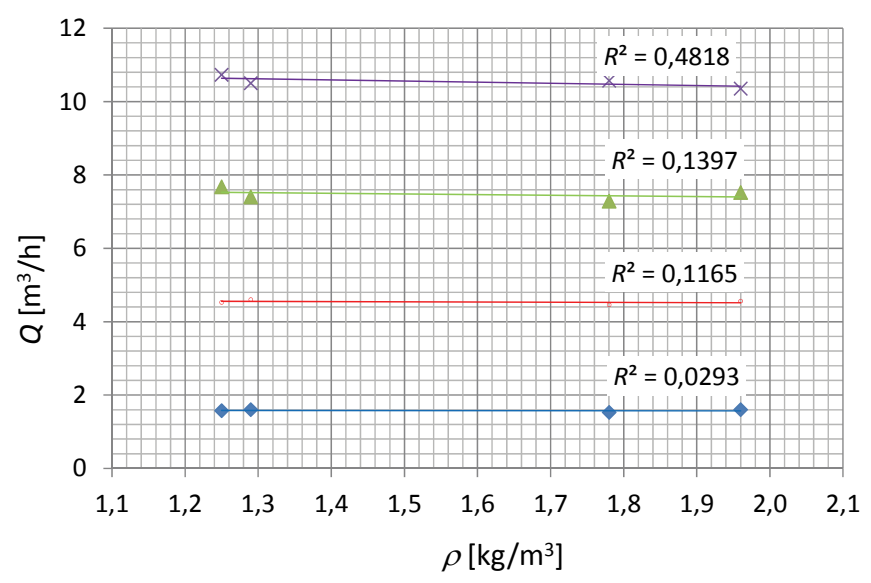

- Przepływ $\left[\mathrm{m}^{3} / \mathrm{h}\right]$ - dysza $4 \mathrm{~mm}$.Przepływ $\left[\mathrm{m}^{3} / \mathrm{h}\right]$ - dysza $6 \mathrm{~mm}$

$\triangle$ Przepływ $\left[\mathrm{m}^{3} / \mathrm{h}\right]-$ dysza $8 \mathrm{~mm} \times \operatorname{Przepływ~}\left[\mathrm{m}^{3} / \mathrm{h}\right]-$ dysza $9 \mathrm{~mm}$

Rys. 2. Korelacja między gęstością medium a charakterystykami przepływu reduktora B przy ciśnieniu wejściowym $0,1 \mathrm{MPa}$ 


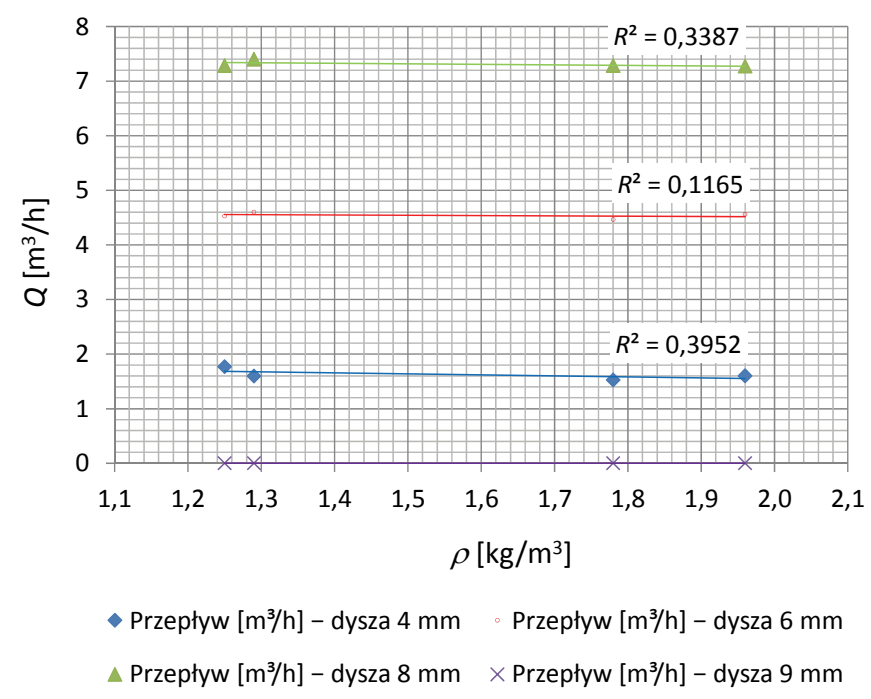

Rys. 3. Korelacja między gęstością medium a charakterystykami przepływu reduktora $\mathrm{C}$ przy ciśnieniu wejściowym $0,1 \mathrm{MPa}$

\section{Wnioski}

Analizując przedstawione wyniki korelacji, należy stwierdzić, że nie występuje zależność między gęstościami a strumieniami objętości powietrza przeliczonymi ze strumieni objętości pozostałych gazów. W przypadkach, w których istnieje zauważalna zależność o sile umiarkowanej, może to być wynikiem wahania ciśnienia wyjściowego reduktora, powodującego zmianę przepływu. W związku z tym stwierdza się, że zastosowany wzór do przeliczania strumienia objętości powietrza ze strumienia objętości innych gazów jest prawidłowy.

Prosimy cytować jako: Nafta-Gaz 2016, nr 9, s. 742-746, DOI: 10.18668/NG.2016.09.09

Artykuł nadesłano do Redakcji 19.04.2016 r. Zatwierdzono do druku 17.06.2016 r.

Artykuł powstał na podstawie pracy statutowej pt. Analiza gęstości medium na ciśnienie wyjściowe reduktora średniego ciśnienia - praca INiG - PiB na zlecenie MNiSW; nr zlecenia: 0049/GP/15, nr archiwalny: DK-4100-49/15.

\section{Literatura}

[1] Analiza wplywu właściwości fizycznych gazu na parametry metrologiczne gazomierzy miechowych. Praca statutowa INiG - PiB, zlec. wew. INiG 54/GM/2004.

[2] Raźna A.: Wplyw nastaw urządzeń zabezpieczajacych (wbudowanych we wspólny korpus) na prace domowych reduktorów średniego ciśnienia. Nafta-Gaz 2009, nr 4, s. 322-331.

[3] Wiśniowicz A.: Ryzyko użytkowania reduktorów średniego ciśnienia. Nafta-Gaz 2015, nr 8, s. 572-577.

[4] Wiśniowicz A.: Wplyw czynników środowiskowych i oddziaływania gazu na funkcjonowanie reduktorów średniego ciśnienia. Nafta-Gaz 2013, nr 6, s. 463-467.

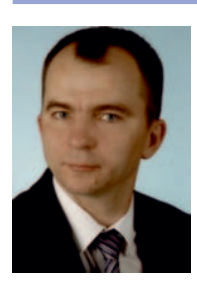

Mgr inż. Dariusz OSIKA

Starszy specjalista inżynieryjno-techniczny w Zakładzie Przesyłania i Dystrybucji Gazu Instytut Nafty i Gazu - Państwowy Instytut Badawczy ul. Lubicz 25 A

31-503 Kraków

E-mail:dariusz.osika@inig.pl

\section{Akty prawne i normatywne}

[5] Rozporządzenie Ministra Gospodarki z dnia 26 kwietnia 2013 r. w sprawie warunków technicznych, jakim powinny odpowiadać sieci gazowe i ich usytuowanie (Dz. U. z 2013 r. poz. 640).

[6] Rozporządzenie Ministra Infrastruktury z dnia 11 sierpnia 2004 r. w sprawie sposobów deklarowania zgodności wyrobów budowlanych oraz sposobu znakowania ich znakiem budowlanym (Dz. U. z 2004 Nr 198, poz. 2041 ze zm.).

[7] Zalecenia Aprobacyjne AT Zał. Nr 122/13 wyd. I/2013 Zalecenia dla wyrobu będacego przedmiotem aprobaty technicznej. Wymagania i badania. Reduktory o przepustowości do $60 \mathrm{~m}^{3} / \mathrm{h}$ na ciśnienie średnie; INiG - PiB 2013.

Mgr inż. Andrzej ŻUREK

Starszy specjalista inżynieryjno-techniczny w Zakładzie Przesyłania i Dystrybucji Gazu

Instytut Nafty i Gazu - Państwowy Instytut Badawczy

ul. Lubicz 25 A

31-503 Kraków

E-mail: andrzej.zurek@inig.pl 